\title{
Finanças Comportamentais: uma InVestigaÇÃo COM base NA TEORIA DO PROSPECTO E NO PERFIL DO INVESTIDOR DE ESTUDANTES DE CURSOS STRICTO SENSU PORTUGUESES
}

\author{
Behavioral Finance: an investigation based on the prospect \\ theory and the investor profile of portuguese stricto sensu \\ graduate students
}

Fabricio Luis Colognese Haubert

Coordenador de Curso de Graduação em Administração. Instituto de Ensino Superior da Grande Florianópolis. Florianópolis, SC.

Brasil.E-mail: fabricio.haubert@hotmail.com

Carlos Rogério Montenegro de Lima

Professor do Programa de Pós-Graduação em Administração. Universidade do Sul de Santa Catarina. Florianópolis, SC. Brasil.

E-mail: carlos.montenegro@unisul.br

Marcus Vinicius Andrade de Lima

Professor do Curso de Ciências da Administração. Universidade Federal de Santa Catarina. Florianópolis, SC. Brasil.

E-mail: marcus.lima@cse.ufsc.br

\section{Resumo}

As Finanças Comportamentais representam uma nova área de estudo que busca analisar os aspectos psicológicos dos indivíduos no processo de tomada de decisões financeiras. Estudos nessa área buscam verificar premissas assumidas pelas teorias mais tradicionais, em particular a da racionalidade dos agentes econômicos, tendo como objetivo aperfeiçoar o modelo econômico-financeiro por meio da incorporação de evidências sobre a irracionalidade do investidor. Nesse contexto, o objetivo deste artigo é compreender o comportamento dos estudantes de pós-graduação stricto sensu portugueses quanto à sua atuação em investimentos com base nas finanças comportamentais. A fim de obter informações sobre o perfil comportamental de investidores e de futuros investidores foi realizada uma pesquisa quantitativa para coleta de dados com uso de um questionário composto de 15 questões aplicadas a 130 estudantes de stricto sensu de Lisboa - Portugal. Foi possível identificar que os perfis conservador e moderado predominam entre os estudantes pesquisados. Verificou-se também que os estudantes apresentaram aversão ao risco no campo dos ganhos e propensão ao risco no campo das perdas. Assim, é possível afirmar que ocorreu o efeito reflexo na presente pesquisa.

Palavras-chave: Finanças Comportamentais. Perfil do Investidor. Teoria de Prospecto. Teoria da Utilidade Esperada.

\section{Abstract}

Behavioral Finance is a new area of study that seeks to analyze the psychological aspects of individuals in making financial decisions. Studies in this area are intended to verify assumptions made by more traditional theories, in particular, the rationality of economic agents, and they aim to improve the economic and financial model through the incorporation of evidence on investor irrationality. In this context, the objective of this article is to understand the behavior of portuguese post-graduate students to its operations in investments based on behavioral finance. In order to learn about the behavioral profile of investors and prospective investors, a survey was conducted to collect quantitative data using a questionnaire comprising 15 questions for 130 stricto sensu graduate students of Lisbon - Portugal. It was possible to identify the predominant conservative and moderate profiles. It was observed that students showed risk aversion in the field of gains and risk propensity in the field of losses. So it is possible to say that the reflection effect occurred in this study.

Keywords: Behavioral Finance. Investor Profile. Prospect Theory. Expected Utility Theory. 


\section{INTRODUÇÃo}

As teorias tradicionais de Finanças, em sua quase totalidade, foram construídas a partir de uma abordagem microeconômica neoclássica cujo paradigma central é a racionalidade dos agentes econômicos (YOSHINAGA et al., 2008). Mais especificamente, assume-se que os indivíduos que atuam nos mercados financeiros são capazes de atualizar corretamente suas crenças após receberem novas informações $e$ que suas decisões são consistentes com o conceito de Utilidade Esperada Subjetiva como apresentado por Savage (1964).

De acordo com o modelo descrito na Teoria da Utilidade Esperada (TUE), as pessoas tomam decisões totalmente racionais, são avessas ao risco e visam maximizar a utilidade. Porém, a Teoria de Finanças Comportamentais contestam essas afirmações.

O estudo das interferências dos incentivos intrínsecos no comportamento econômico dos humanos é campo de estudo de uma ciência relativamente nova, chamada de Economia Comportamental ou Finanças Comportamentais. Finanças Comportamentais é uma área de estudo dentro da teoria do prospecto que se contrapõe ao pressuposto da racionalidade ilimitada dos tomadores de decisão adotado pelas Finanças Modernas. Segundo Arruda (2006), o estudo das Finanças Comportamentais foi criado por dois psicólogos israelenses, Daniel Kahneman e Amos Tversky em estudos feitos nos anos de 1974 e 1979, por meio de um trabalho intitulado Teoria do Prospecto. A Teoria do Prospecto é uma teoria basilar das Finanças Comportamentais que apresenta um modelo alternativo à Teoria da Utilidade Esperada para descrever a forma como as pessoas decidem frente a probabilidades arriscadas. (MACEDO, 2003)

De acordo com o modelo descrito na TUE, decisões racionais exigem que as pessoas utilizem e processem todas as informações disponíveis de um modo lógico e sistemático, buscando sempre as melhores opções baseadas nos objetivos a serem alcançados. (ZINDEL, 2008)

Na Teoria do Prospecto, a aversão ao risco só ocorre no campo dos ganhos, porém quando é apresentada a um indivíduo a possibilidade de perda, este indivíduo tende a ser propenso ao risco (DIERKES; ERNER; ZEISBERGER, 2010). De acordo com essa teoria, os indivíduos são avessos ao risco no campo dos ganhos e propensos ao risco no campo das perdas. Essa propensão ao risco no campo das perdas é um dos "erros" identificados na Teoria da Utilidade Esperada.

Nessa perspectiva, o estudo sobre a mudança de preferências resultou em três efeitos distintos identificados por Kahneman e Tversky (1979), são eles o efeito certeza, reflexo e isolamento.

No efeito certeza em probabilidades de ganhos, as pessoas tendem a preferir os resultados obtidos com certeza aos resultados prováveis. Todavia, quando ganhar torna-se possível, mas não provável, a maioria prefere a aposta de maior valor.

Já de acordo com o efeito reflexo, no campo das perdas, as pessoas tendem a arriscar a sofrerem uma perda certa. Dessa forma, Kahneman e Tversky (1979) descobriram que os sinais dos resultados quando são invertidos em ganhos para perdas, as pessoas se tornam propensas ao risco e que tal comportamento fere o axioma da TUE de aversão ao risco.

O último efeito descrito em Kahneman e Tversky (1979) corresponde ao efeito isolamento, em que há uma tendência das pessoas apresentarem preferências inconsistentes, para problemas iguais, porém apresentados de formas diferentes, um de cada vez.

Nesse contexto, estudiosos deste assunto buscam desenvolver modelos econômicos que levem em consideração o fato de que o homem não é totalmente racional. O grande desafio na elaboração desses modelos está relacionado com a grande complexidade da irracionalidade humana.

Os trabalhos de Kahneman e Tversky de 1974 e 1979 formaram a base teórica para a análise do comportamento de investidores e tiveram importância seminal para as Finanças Comportamentais. Porém, este novo campo de estudo só se consolidou realmente com os trabalhos de Richard Thaler (1993).

A partir dos trabalhos desses dois psicólogos, o economista Richard Thaler se pôs na vanguarda de um grupo de economistas acadêmicos que reagiu às falhas do modelo racional $e$ inaugurou o novo campo de estudos das finanças comportamentais. (BERNSTEIN, 1997)

Edwards (1968) propõe um problema baseado em probabilidades para demonstrar que os indivíduos têm um valor de referência que ancora suas percepções levando-os a estabelecer estimativas conservadoras. 
Shefrin (2000) afirma que a deficiência de o indivíduo em analisar informação adicional é análoga à deficiência que os analistas financeiros apresentam quando fazem novas projeções sobre lucros futuros de uma empresa em função do surgimento de nova informação relevante. Assim, os analistas não revisam suficientemente suas estimativas para refletir novas informações.

Por outro lado, segundo Plous (1993), nenhum outro problema de julgamento e tomada de decisão tem maior poder de catástrofe do que o excesso de confiança, o que pode levar o investidor a crer que possui vantagens comparativas na análise e avaliação de ativos em relação ao mercado, mantendo posições perdedoras. Além disso, o excesso de confiança pode levar a demasiada exposição em determinados ativos, tendo em vista a crença do investidor em que seu posicionamento no ativo conduzirá a ganhos futuros consideráveis. Nesse contexto, pode haver uma diversificação de investimentos errada por parte do investidor. Isso ocorre pelo fato de o investidor concentrar a carteira em determinados ativos que acredita possuir rentabilidade maior que os demais.

Conhecer o perfil do investidor e as características do investimento pode trazer uma maior segurança na hora de aplicar o dinheiro, pois conhecendo o perfil do investidor pode-se identificar qual é o investimento que mais se adéqua ao seu perfil e objetivos com o investimento. Uma aplicação feita de forma correta de acordo com os objetivos do investidor pode gerar uma boa rentabilidade e o alcance da independência financeira.

Atualmente, o mercado de capitais está bem amplo. As opções de investimento são variadas, porém nem todas são ideais para todo mundo, pois cada tipo de investimento possui suas peculiaridades. Assim, é necessário conhecer bem o investimento, bem como os objetivos do investidor com ele para que não se tenha surpresas desagradáveis com prejuízos inesperados.

Dessa forma, a presente pesquisa busca analisar o comportamento dos investidores frente à tomada de decisão financeira. Para isso foi definido como população da pesquisa os estudantes de stricto sensu de Administração, Economia e Contabilidade de Lisboa - Portugal.
A escolha deste público é devido ao fato de que os mesmos já possuem algum conhecimento, mesmo que teórico sobre investimentos no curso de graduação que frequentaram. É importante ressaltar também que esse público de jovens investidores nem sempre possui compromissos familiares.

Para tentar compreender melhor o comportamento dos estudantes frente à tomada de decisão financeira, definiu-se a seguinte pergunta de pesquisa: Como se comportam os estudantes de pós-graduação stricto sensu portugueses no processo de alocação de investimentos?

Dessa forma, esta pesquisa tem como objetivo compreender o comportamento dos estudantes de pós-graduação stricto sensu portugueses quanto à sua opção nos investimentos com base nas finanças comportamentais.

Diante disso, a presente pesquisa torna-se relevante ao discutir aspectos ligados às finanças comportamentais buscando uma melhor compreensão do perfil do investidor aliado com os tipos de investimentos disponíveis atualmente no mercado. Optar pelo investimento correto de acordo com suas características e necessidades é fundamental para o seu bom andamento. Conhecer o nível de tolerância do investidor para quedas no mercado é fundamental para não se perder dinheiro aplicando em investimentos muito instáveis onde retirar o dinheiro investido em um momento errado pode gerar prejuízos.

Este artigo foi dividido em cinco seções. Nesta primeira seção apresentou-se a introdução do trabalho em que é exposto o objetivo, a pergunta de pesquisa e a justificativa. Na segunda seção apresenta-se o referencial teórico dividido em três tópicos: Finanças Comportamentais, Perfil do Investidor e Teoria do Prospecto. A terceira seção descreve os procedimentos metodológicos. Na quarta são apresentados os resultados da pesquisa. As considerações finais são apresentadas na seção cinco.

\section{Referencial Teórico}

Nesta seção será feita uma revisão da literatura onde serão abordados os seguintes temas: Finanças Comportamentais, Perfil do investidor, Teoria do Prospecto. 


\subsection{Finanças Comportamentais}

As finanças modernas, para Haugen (2000), baseiam-se em modelos de risco-retorno e partem do princípio da racionalidade do investidor e da eficiência do mercado. Diante deste conceito de finanças modernas, surgiu a necessidade de um novo modelo às novas finanças. $\mathrm{E}$, ainda, a partir da dificuldade dos modelos teóricos utilizados, surgiram as finanças comportamentais para explicar o crescente número de anomalias, ou seja, de comportamentos empíricos não explicados pela teoria moderna. (HAUGEN, 2000)

$\mathrm{O}$ estudo das Finanças Comportamentais contesta a teoria de que as tomadas de decisões vêm do pressuposto da racionalidade (ATMAN; GONÇALVES, 2012). Isso significa que é relevante levar em consideração os conceitos não somente da economia $e$ finanças, como também da psicologia cognitiva, que retrata o desempenho humano, ou seja, está sujeito a vieses comportamentais que interferem numa decisão racional.

Lintner (1998) define finanças comportamentais como o estudo através do qual os investidores interpretam e agem frente às informações para decidir sobre investimentos.

O debate sobre a racionalidade dos tomadores de decisão dentro da psicologia vem sendo tratado desde a década de cinquenta. Nessa época, quem dominava a psicologia era a escola behaviorista. Os behavioristas acreditavam que o comportamento humano se dava pelas relações estímulo-resposta (SKINNER, 1957). Skinner relata que as decisões que não levassem em consideração a razão seriam punidas com estímulos negativos. Assim, estes estímulos induziriam os humanos a utilizar a razão ao tomar decisões.

Porém, a crença de que o comportamento humano pudesse ser sempre explicado por uma sucessão de estímulos e respostas começou a ser criticada. A partir de estudos, psicólogos verificaram que em algumas situações específicas os seres humanos violavam princípios da racionalidade ao tomarem decisões. (MACEDO, 2003)

Percebendo isso, Allais (1953) questionou em seus estudos o pressuposto de racionalidade dos tomadores de decisão. Em um experimento com prospectos arriscados, ele demonstrou que o axioma da substituição da Teoria da Utilidade era violado pela maioria dos participantes.
Buscando entender melhor a racionalidade dos seres humanos, Amos Tversky e Daniel Kahneman (1974) foram além das demonstrações de violação dos axiomas verificadas por Allais. Esses dois psicólogos se preocuparam em criar um modelo descritivo da forma utilizada pelos humanos para tomar decisões.

A percepção que os humanos utilizavam regras heurísticas para tomar decisão veio logo no início de seus trabalhos. Sternberg (2000) define regras heurísticas como sendo atalhos mentais ou regras empíricas para encontrar uma solução para dado problema. A interferência dessas regras em processos de decisão foi descrita em Tversky e Kahneman (1974). Para esses psicólogos, a utilização de regras heurísticas pode gerar vieses nas decisões. Um viés de decisão é uma tendência sistemática de violar os axiomas da racionalidade ampla. Um fato importante é que o viés pode igualmente afetar de forma semelhante um grande número de pessoas. Um segundo fator gerador de vieses de decisão foi agrupado sob o nome de Teoria do Prospecto (KAHNEMAN; TVERSKY, 1979). De acordo com essa teoria, os humanos utilizam duas fases no processo de escolha: a primeira, para editar os prospectos arriscados; a segunda, para avaliar estes prospectos.

A fase para editar consiste em uma análise preliminar das probabilidades oferecidas quando, frequentemente, se faz uma simplificação das probabilidades. Na segunda fase, as probabilidades editadas são avaliadas e a probabilidade de valor mais alto é escolhida. (MACEDO, 2003)

Apesar de todos os avanços no estudo da tomada de decisão por parte dos psicólogos cognitivos, faltava alguém para fazer a união entre a Economia e a Psicologia Cognitiva. Percebendo essa lacuna, Richard Thaler no ano de 1978 durante a elaboração da sua tese de doutorado, ao conhecer o artigo "Judgment under uncertainty: heuristics and biases", de Tversky e Kahneman (1974), começou a se interessar pelas anomalias do comportamento humano.

Thaler (1981) conseguiu aproximar a Economia da Psicologia. Assim, passou a fazer parte de um grupo de economistas acadêmicos que reagiram às falhas do comportamento racional. O artigo de Kahneman e Tversky (1979) é um marco da aproximação da Psicologia e da Economia e Finanças. Tversky, Kahneman e Thaler inauguraram um novo campo de estudos, 
intitulado por eles de "Finanças Comportamentais". (BERNSTEIN, 1997)

\subsection{Teoria do Prospecto}

Foi com base no artigo "Prospect Theory: Decision Making Under Risk", dos Irlandeses Daniel Kahneman e Amos Tversky, publicado em 1979, que a teoria do prospecto começou a ser discutida. A Teoria do Prospecto representa a base teórica para a análise do comportamento de investidores, desempenhando papel fundamental para o início do desenvolvimento das Finanças Comportamentais, pois busca explicar os vieses cognitivos (heurísticos) no processo de tomada de decisão. (OLIVEIRA; SILVA; SILVA, 2005)

Kahneman e Tversky (1979), em sua Teoria dos Prospectos, distinguem duas fases no processo de escolha - uma fase inicial denominada de edição e uma fase subsequente denominada de avaliação, nas quais o tomador de decisão constrói uma análise preliminar dos prospectos oferecidos, o que proporciona uma representação mais simples destes prospectos a fim de que possam ser avaliados e escolhidos tomando-se por base os atos, contingências e resultados que são relevantes para a decisão.

Esses pesquisadores procuram compreender as atitudes dos investidores no dia a dia do mercado financeiro, no que tange os contextos cognitivos $e$ psicológicos determinantes de escolhas com e sem riscos. Para tanto, apresentaram aos indivíduos problemas tendo como base o benefício (ganho ou perda) e o risco (probabilidades) envolvidos nessa decisão. (FERREIRA et al., 2008)

Conforme Barberis, Shleifer e Vishny (1998), os desvios significativos e sistemáticos da eficiência dos mercados são esperados e passíveis de acontecer por longos períodos de tempo. Em vista disso, a Teoria do Prospecto tenta compreender o comportamento de diferentes grupos de pessoas frente a problemas envolvendo decisões de investimento sob risco.

Para Carmo (2005), a Teoria do Prospecto detectou dois padrões de comportamento ignorados pela abordagem clássica: a emoção que interfere no autocontrole e a dificuldade que as pessoas têm para entender plenamente com o que estão lidando.

De acordo com Mineto (2005), essa teoria é a principal referência em qualquer modelo que tenta entender a fixação dos preços dos ativos, ou o comportamento dos investidores quanto às suas preferências, ou sobre como os investidores avaliam o risco.

Para entender os preços dos ativos é importante conhecer as preferências dos investidores e como estes agem perante o risco. De acordo com a Teoria da Utilidade Esperada, os investidores deveriam seguir a curva de utilidade, conforme a Figura 1. No entanto, frequentemente são constatadas no mercado ações que fogem a essa regra.

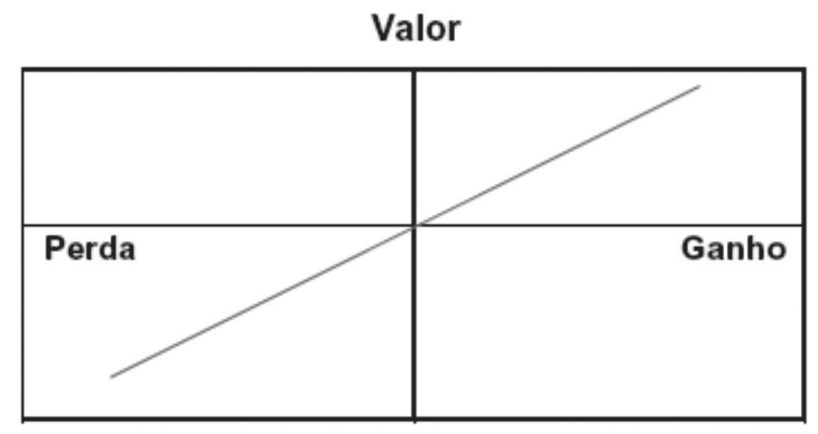

Figura 1: Curva de Risco-Utilidade - Teoria da Utilidade Esperada

Fonte: Adaptada de Kahneman e Tversky (1979)

Dentre todas as abordagens alternativas à Teoria da Utilidade Esperada, a mais utilizada pelos pesquisadores de Finanças Comportamentais é a Teoria do Prospecto, proposta por Tversky e Kahneman (1974). Os autores argumentam que cada decisão tende a ser avaliada de forma independente, opondo-se à Teoria da Utilidade Esperada.

Segundo Gava e Vieira (2006), os elementos centrais da Teoria do Prospecto são: as pessoas são geralmente avessas ao risco para ganhos e propensas ao risco para perdas; pessoas atribuem pesos não lineares a ganhos e perdas potenciais; resultados certos são geralmente excessivamente ponderados em comparação com resultados incertos; a função de utilidade é normalmente voltada para ganhos e adversa para perdas. A Figura 2 representa este comportamento no campo dos ganhos e das perdas.

A Teoria do Prospecto ao demonstrar a violação dos axiomas da Teoria da Utilidade Esperada apresenta uma das mais importantes descobertas em Finanças Comportamentais, a aversão à perda, e que as pessoas sentem muito mais a dor ao perderem um valor que o prazer de ganhá-lo (CARMO, 2005). Vale ressaltar que a aversão à perda não possui o mesmo significado que 
aversão ao risco e, que frente a uma perda, frequentemente as pessoas topam o risco de perder ainda mais, apenas pela chance de se salvar antes da perda efetiva. Pode-se comparar tal atitude com o comportamento de um jogador compulsivo. Ao fazer suas jogadas, ele prefere dobrar a aposta, para não ter de sair da mesa falido. (LIMA, 2003)

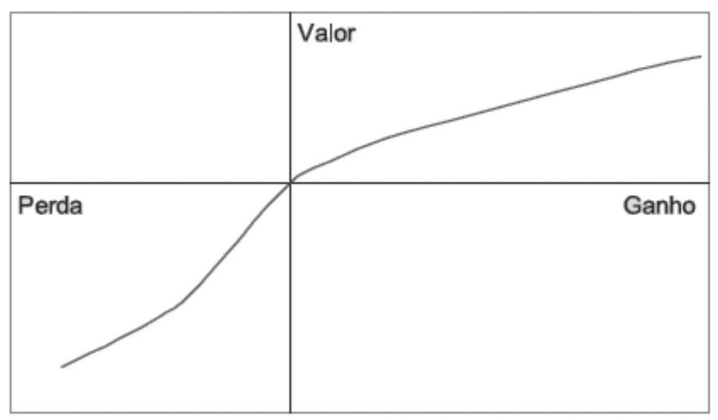

Figura 2: Curva de Risco-Utilidade - Teoria do Prospecto Fonte: Adaptada de Kahneman e Tversky (1979)

\subsection{Perfil do Investidor}

Em todo investimento deve-se analisar sua rentabilidade, segurança e liquidez. Rentabilidade é apurada pelo resultado da divisão do valor de resgate ou venda pelo valor da aplicação ou compra. Representa o resultado financeiro da operação. A segurança pode ser mensurada como quanto mais previsível o valor de resgate/venda, maior a segurança e menor o risco do investimento. Já a liquidez é a capacidade de transformar o investimento em dinheiro. (CAVALCANTE; MISUMI; RUDGE, 2005, p. 224)

Os investimentos devem ter objetivos definidos. Por exemplo: fundo de emergência, férias, previdência, expansão do capital etc. Assim, antes de definir o tipo de investimento, o investidor deve considerar algumas questões importantes como: qual o objetivo ao fazer esse investimento, qual é a expectativa de rentabilidade, qual é o valor disponível para investir, quando vai precisar desse dinheiro, possui conhecimento sobre este tipo de investimento, a diversificação da carteira é consistente com seu perfil de risco.

Independentemente dos nossos modelos mentais e da racionalidade limitada, o aspecto mais importante para o investidor, conforme Toscano Júnior (2004), é identificar, entre os diversos tipos de investimentos, aquele que melhor atenderá sua expectativa de retor- no, ou seja, qual se adapta melhor ao seu perfil. Esse perfil está relacionado à política de investimentos. É nela que o investidor identifica sua intenção quanto a um determinado ativo.

As principais características, conforme Toscano Júnior (2004), para melhor interpretação do perfil de investidores são: conservador, moderado e agressivo.

$\mathrm{O}$ investidor conservador não tem por objetivo ganhar, e sim preservar seu capital. Não admite perder ou ver a sua aplicação encolher, prefere risco zero como os fundos de renda fixa DI (fundos de renda fixa) e de curto prazo. Aplicações em ações e derivativos nem passam pela sua cabeça.

Já um investidor moderado quer ganhar dinheiro e aceita correr certo tipo de risco. Dessa forma, admite que sua aplicação fique por alguns meses sem remuneração ou tenha uma pequena perda. Assim, sempre procura fundos que representam rendimentos superiores à média de mercado. Suas preferências são os fundos multimercados.

Um investidor agressivo pensa como um especulador, e não como um poupador. Ele investe muito em ações, fundos de ações e derivativos. Normalmente, esse tipo de investidor é muito capitalizado, com investimentos bem diversificados e não tem medo de perder tudo que aplicou, assume o prejuízo e parte em busca de novos investimentos.

Para definir o perfil de investidor, o mais importante é considerar sua tolerância ao risco. Existem pessoas que estão dispostas a tomar maiores riscos do que outras e, portanto, tendem a aguentar melhor as flutuações do mercado. A idade do investidor é fundamental na hora de decidir onde aplicar o dinheiro. Investimentos mais arriscados são mais recomendados para investidores jovens, pois caso tenham prejuízos terão mais tempo para recuperar seu dinheiro. (HALFELD, 2005)

\section{Procedimentos Metodológicos}

Esta pesquisa classifica-se, quanto à abordagem, como predominantemente quantitativa, pois utiliza dados numéricos e estatísticos para garantir sua representatividade. (CHIZZOTTI, 2008)

Quanto aos objetivos, a pesquisa é de caráter exploratório, uma vez que busca identificar os comportamentos dos investidores e propensos investidores. 
Classifica-se ainda como descritiva, pois descreve analiticamente com base nas Finanças Comportamentais o comportamento do investidor. Dentro do processo exploratório, é realizado um levantamento. Gil (1999) defende que o levantamento é uma metodologia positivista caracterizada pela interrogação direta das pessoas onde se deseja conhecer o comportamento.

Nesse caso, pretende-se verificar se os estudantes praticam algum tipo de investimento, os tipos de investimentos feitos por estes estudantes, $e$ avaliar as diferenças de perfil de investidor entre os estudantes de stricto sensu, identificando se o perfil do investidor é agressivo, moderado ou conservador, de acordo com a expectativa de retorno e tipo de investimento escolhido.

O horizonte de tempo é transversal, pois, segundo Collis e Hussey (2005), a pesquisa foi projetada para obter informações sobre variáveis em diferentes contextos, mas simultaneamente. Os dados foram coletados apenas uma vez, em um período de tempo curto, antes de serem analisados e relatados.

A fim de responder o problema de pesquisa, foram coletados dados primários junto aos estudantes de stricto sensu dos cursos de Administração, Ciências Contábeis e Economia.

A população pesquisada é composta por 342 estudantes de stricto sensu das sete universidades: Instituto Superior de Ciência do Trabalho e Estudo (ISCTE), Instituto Superior de Economia e Gestão (ISEG), Universidade Católica Portuguesa, Universidade Autônoma de Lisboa (UAL), Universidade Lusófona de Humanidades Tecnológicas, Universidade Nova de Lisboa (UNL) e Instituto Superior de Contabilidade e Administração de Lisboa (ISCAL). O questionário foi aplicado de forma aleatória a 130 estudantes compondo assim a amostra.

O instrumento de pesquisa foi aplicado aos alunos por intermédio de uma página hospedada na internet disponível em <http://www.questionariofinancas.com. br/>, no período de fevereiro a maio de 2011.

Para compreender melhor o perfil de investimento dos estudantes de stricto sensu foram analisadas as seguintes variáveis: idade do investidor, tempo de investimento, renda mensal e percentual de investimento de acordo com a renda mensal. Outra variável identificada é o grau de aceitação ao risco, analisando assim a permanência dos investidores em determinados tipos de investimentos frente às altas e baixas do mercado, identificar a tolerância dos mesmos e a permanência ou não em seus investimentos frente à possibilidade de ganho e de perda de capital.

A análise dos dados foi feita de forma descritiva através de análise e descrição de gráficos e tabelas obtidos com a tabulação das respostas dos questionários utilizando o software SPSS (Statistical Package for the Social Sciences) - ferramenta para análise estatística que oferece diferentes análises de dados, teste de hipóteses e criação de modelos de projeção.

\section{Apresentação e Análise dos Resultados}

Nesta seção estão expostas as informações obtidas a partir da análise dos dados de acordo com as circunstâncias investigadas na presente pesquisa. $\mathrm{Na}$ primeira parte apresenta-se a análise levando em conta o perfil do investidor, já na segunda parte será feita análise de acordo com a Teoria do Prospecto.

\subsection{Análise com Base no Perfil do Investidor}

Para Macedo (2003), quanto menor a idade do investidor, maior deve ser sua propensão ao risco, pois caso venha a ter perdas, ele terá mais tempo para recuperar o capital perdido. Nesse sentido, o primeiro ponto analisado teve o intuito de verificar se quanto maior a idade do investidor, menor é sua propensão ao risco.

Logo, serão analisados os perfis dos investidores participantes da pesquisa de acordo com sua idade conforme Tabela 1.

Tabela 1: Perfil do investidor português versus idade

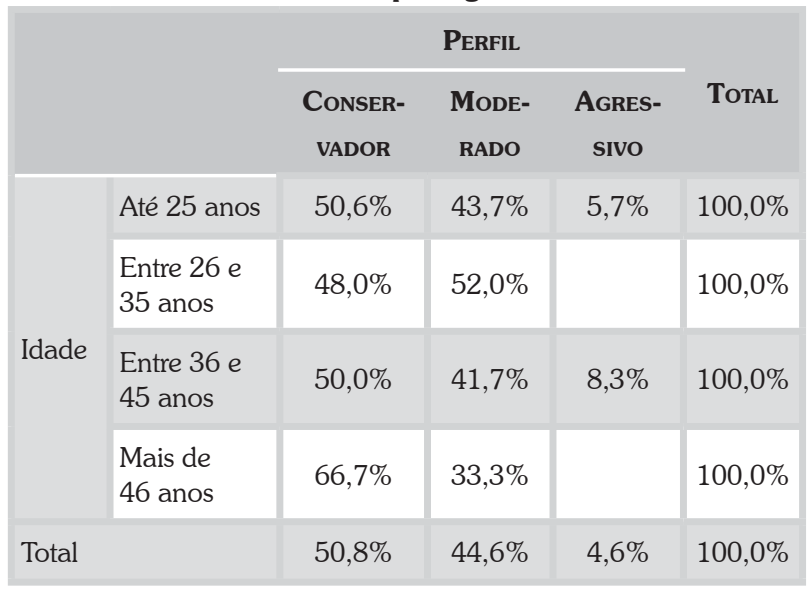

Fonte: Elaborada pelos autores deste artigo 
Com esses dados pode-se perceber que mesmo para investidores portugueses entre 36 e 45 anos, onde foi encontrado o maior percentual de investidores com perfil agressivo (8,3\%), os conservadores são $50 \%$. Ainda nessa perspectiva, os investidores portugueses com perfil agressivo com mais de 46 anos continuam optando por investimentos menos arriscados de forma que quando analisado investidores nessa faixa etária, esse percentual se reduz a zero.

Tabela 2 - Resultados do teste qui-quadrado para perfil do investidor e idade

\begin{tabular}{l|c|c|c|}
\multicolumn{4}{c}{ ChI-Square Tests } \\
& Value & DF & $\begin{array}{c}\text { Asymp. Sig. } \\
\text { (2-SIDED) }\end{array}$ \\
\hline Pearson Chi-Square & $2,887 a$ & 6 &, 823 \\
\hline Likelihood Ratio & 4,206 & 6 &, 649 \\
\hline N of Valid Cases & 130 & & \\
\hline
\end{tabular}

a. 6 cells $(50,0 \%)$ have expected count less than 5 . The minimum expected count is, 28 .

Fonte: Elaborada pelos autores deste artigo

Por meio do teste estatístico qui-quadrado foi encontrado um $\chi^{2}=2,887$, conforme Tabela 2. Levando em consideração o valor do nível de significância encontrado $(0,823)$ em gl (graus de liberdade) igual a 6 , não é possível rejeitar Ho. Nesse caso, é possível aceitar a hipótese de não associação das variáveis, ou seja, não foi observada uma relação entre idade e propensão ao risco.

Para verificar se o tempo de investimento influencia no perfil do investidor, buscou-se analisar se investidores com menos tempo de mercado estão menos ou mais propensos ao risco do que investidores com mais tempo de mercado. Assim, na Tabela 3 são analisados os comportamentos dos investidores conforme seu tempo de investimento.

Analisando a Tabela 8, pode-se perceber que investidores portugueses com menos de um ano de mercado têm uma forte tendência ao perfil moderado que aparece com $70 \%$. Porém, se analisarmos os investidores com perfil agressivo com mais de cinco anos de mercado, percebe-se que são apenas 3,7\%, já os teoricamente menos experientes com menos tempo de mercado, entre três e cinco anos, esse número sobe para $6,7 \%$.
Tabela 3: Tempo de investimento versus perfil do investidor

\begin{tabular}{|c|c|c|c|c|c|}
\hline & & \multicolumn{3}{|c|}{ Perfil } & \multirow[b]{2}{*}{ Total } \\
\hline & & $\begin{array}{l}\text { CONSER- } \\
\text { VADOR }\end{array}$ & $\begin{array}{l}\text { ModE- } \\
\text { RADO }\end{array}$ & $\begin{array}{c}\text { Agres- } \\
\text { SIVo }\end{array}$ & \\
\hline \multirow{5}{*}{ 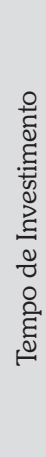 } & $\begin{array}{l}\text { Menos de } \\
1 \text { ano }\end{array}$ & $30,0 \%$ & $70,0 \%$ & & $100,0 \%$ \\
\hline & $\begin{array}{l}\text { Entre } 1 \text { ano } \\
\text { e } 3 \text { anos }\end{array}$ & $47,4 \%$ & $47,4 \%$ & $5,3 \%$ & $100,0 \%$ \\
\hline & $\begin{array}{l}\text { Entre } 3 \text { anos } \\
\text { e } 5 \text { anos }\end{array}$ & $40,0 \%$ & $53,3 \%$ & $6,7 \%$ & $100,0 \%$ \\
\hline & $\begin{array}{l}\text { Mais de } \\
5 \text { anos }\end{array}$ & $66,7 \%$ & $29,6 \%$ & $3,7 \%$ & $100,0 \%$ \\
\hline & $\begin{array}{l}\text { Não sou } \\
\text { investidor }\end{array}$ & $50,8 \%$ & $44,1 \%$ & $5,1 \%$ & $100,0 \%$ \\
\hline \multicolumn{2}{|c|}{ Total } & $50,8 \%$ & $44,6 \%$ & $4,6 \%$ & $100,0 \%$ \\
\hline
\end{tabular}

Fonte: Elaborada pelos autores deste artigo

Pode-se perceber que o percentual mais elevado entre os investidores portugueses agressivos está entre investidores que possuem entre três a cinco anos de mercado com $6,7 \%$.

Tabela 4: Resultados do teste qui-quadrado para tempo de investimento e perfil do investidor

\begin{tabular}{|c|c|c|c|}
\hline \multicolumn{4}{|c|}{ Chi-Square Tests } \\
\hline & Value & DF & $\begin{array}{c}\text { AsYMP. Sig. } \\
\text { (2-SIDED) }\end{array}$ \\
\hline Pearson Chi-Square & $6,367 a$ & 8 & ,606 \\
\hline Likelihood Ratio & 6,821 & 8 &, 556 \\
\hline $\mathrm{N}$ of Valid Cases & 130 & & \\
\hline
\end{tabular}

a. 6 cells $(40,0 \%)$ have expected count less than 5 . The minimum expected count is, 46 .

Fonte: Elaborada pelos autores deste artigo

Por meio do teste estatístico qui-quadrado foi encontrado um $\chi^{2}=6,367$ conforme Tabela 4. Levando em consideração o valor do nível de significância encontrado $(0,606)$ em gl (graus de liberdade) igual a 8 , não é possível rejeitar Ho. Nesse caso, é possível aceitar a hipótese de não associação das variáveis, ou seja, não foi observada uma relação entre tempo de investimento e propensão ao risco. No entanto, é possível perceber uma predominância no perfil conservador, independente do tempo de investimento.

Buscando verificar se há diferenças na propensão ou aversão ao risco entre investidores com diferentes 
níveis de renda, foram cruzados dados de renda mensal com perfil do investidor e seu grau de aceitação ao risco.

Tabela 5: Renda individual versus perfil do investidor

\begin{tabular}{|c|c|c|c|c|c|}
\hline & \multicolumn{3}{|c|}{ Perfil } & \multirow[b]{2}{*}{ TOTAL } \\
\hline & & $\begin{array}{c}\text { CONSER- } \\
\text { VADOR }\end{array}$ & $\begin{array}{c}\text { Mode- } \\
\text { RADO }\end{array}$ & $\begin{array}{c}\text { Agres- } \\
\text { SIVo }\end{array}$ & \\
\hline \multirow{6}{*}{ 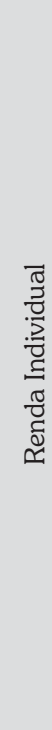 } & $\begin{array}{l}\text { Menos que } \\
R \$ 1.000,00\end{array}$ & $52,1 \%$ & $47,9 \%$ & & $100,0 \%$ \\
\hline & $\begin{array}{l}\text { Entre } \mathrm{R} \$ \\
1.001,00 \mathrm{e} \\
\mathrm{R} \$ 2.000,00\end{array}$ & $42,9 \%$ & $57,1 \%$ & & $100,0 \%$ \\
\hline & $\begin{array}{l}\text { Entre } R \$ \\
2.001,00 \mathrm{e} \\
\mathrm{R} \$ 5.000,00\end{array}$ & $56,7 \%$ & $40,0 \%$ & $3,3 \%$ & $100,0 \%$ \\
\hline & $\begin{array}{l}\text { Entre } \mathrm{R} \$ \\
5.001,00 \\
\text { e } \mathrm{R} \$ \\
10.000,00\end{array}$ & $40,0 \%$ & $50,0 \%$ & $10,0 \%$ & $100,0 \%$ \\
\hline & $\begin{array}{l}\text { Mais de } \mathrm{R} \$ \\
10.000,00\end{array}$ & $50,0 \%$ & $50,0 \%$ & & $100,0 \%$ \\
\hline & $\begin{array}{l}\text { Não possuo } \\
\text { renda } \\
\text { individual }\end{array}$ & $50,0 \%$ & $34,6 \%$ & $15,4 \%$ & $100,0 \%$ \\
\hline \multicolumn{2}{|c|}{ Total } & $50,8 \%$ & $44,6 \%$ & $4,6 \%$ & $100,0 \%$ \\
\hline
\end{tabular}

Fonte: Elaborada pelos autores deste artigo

Os investidores portugueses, quanto maior a renda, tendem a correr mais risco em seus investimentos, uma vez que o percentual de investidores com o perfil agressivo aumenta de acordo com o aumento da renda. Assim a Tabela 5 mostra que investidores com renda entre $R \$ 2.000,00$ e $R \$ 5.000,00,3,3 \%$ são agressivos. Esse percentual sobe para 10,0\% para investidores com renda entre $R \$ 5.001,00$ e $R \$ 10.000,00$. No entanto, entre os investidores com renda superior a $\mathrm{R} \$ 10.000$, não há investidores com perfil agressivo.

Tabela 6: Resultados do teste qui-quadrado para renda individual e perfil do investidor

\begin{tabular}{l|c|c|c|}
\multicolumn{3}{c}{ Chi-Square Tests } \\
& Value & DF & $\begin{array}{c}\text { Asymp. Sig. } \\
\text { (2-Sided) }\end{array}$ \\
\cline { 1 - 4 } & & &, 268 \\
\hline Pearson Chi-Square & $12,262 \mathrm{a}$ & 10 &, 247 \\
\hline Likelihood Ratio & 12,596 & 10 & \\
\hline N of Valid Cases & 130 & & \\
\hline
\end{tabular}

a. 9 cells $(50,0 \%)$ have expected count less than 5 . The minimum expected count is, 09 .

Fonte: Elaborada pelos autores deste artigo
Por meio do teste estatístico qui-quadrado foi encontrado um $\chi^{2}=12,262$ conforme Tabela 6. Levando em consideração o valor do nível de significância encontrado $(0,268)$ em gl (graus de liberdade) igual a 10 , não é possível rejeitar Ho. Nesse caso, é possível aceitar a hipótese de não associação das variáveis, ou seja, não foi observada uma relação entre renda individual e perfil do investidor. No entanto, é possível perceber uma predominância no perfil conservador, independente da renda individual.

A seguir será analisada essa propensão ao risco de uma forma indireta com o cruzamento da renda mensal com o grau de aceitação ao risco do investidor, buscando verificar se há alguma assimetria entre os dois.

\subsection{Análise com Base na Teoria do Prospecto}

Os axiomas da TUE preveem que os investidores são racionais, avessos ao risco e visam maximizar sua utilidade (BERNOULLI, 1954). O enfoque recai sobre o efeito reflexo, no qual investidores tendem a apresentar aversão ao risco no campo dos ganhos e propensão ao risco no campo das perdas (KAHNEMAN; TVERSKY, 1979). Nesse sentido, a presente pesquisa teve o intuito de verificar se os investidores participantes da pesquisa serão afetados pelo efeito reflexo.

Esse efeito se confirmará se houver assimetria das decisões dos investidores nos problemas de probabilidades positivas, se comparados com os problemas de probabilidades negativas.

Logo, serão analisadas as preferências entre probabilidades positivas e negativas dos investidores, participantes da pesquisa conforme Tabelas 7 e 8 . Conforme o critério de apresentação dos resultados utilizado por Kahneman e Tversky (1979), a presença de um asterisco após a frequência de respostas em cada problema representa que a preferência pelo prospecto é significativa ao nível de 5\%, utilizando-se o teste do qui-quadrado calculado pelo software SPSS. 
Tabela 7: Preferências entre probabilidades positivas e negativas com possibilidades de $20 \%$ e $25 \%$ de ganho ou perda para investidores portugueses

\begin{tabular}{|c|c|c|c|c|c|c|}
\hline & \multicolumn{2}{|c|}{ Escolha Entre } & & \multicolumn{2}{|c|}{ Escolha Entre } & \\
\hline & $\begin{array}{c}\text { + Risco } \\
\text { (A) } \\
\text { Um bilhete de loteria } \\
\text { com probabilidade } \\
\text { de } 20 \% \text { de ganhar } \\
\$ 4.000,00 .\end{array}$ & $\begin{array}{c}\text { - Risco } \\
\text { (B) } \\
\text { Um bilhete de loteria } \\
\text { com probabilidade } \\
\text { de } 25 \% \text { de ga- } \\
\text { nhar } \$ 3.000,00 .\end{array}$ & Total & $\begin{array}{c}\text { - Risco } \\
\text { (A) } \\
\text { A probabilidade } \\
\text { de } 20 \% \text { de perder } \\
\$ 4.000,00 \text {. }\end{array}$ & $\begin{array}{c}\text { + Risco } \\
\text { (B) } \\
\text { A probabilidade } \\
\text { de } 25 \% \text { de perder } \\
\$ 3.000,00 .\end{array}$ & Total \\
\hline Total & $47,70 \%$ & $52,30 \%$ & $100,00 \%$ & $40,00 \% *$ & $60,00 \% *$ & $100,00 \%$ \\
\hline
\end{tabular}

Fonte: Elaborada pelos autores deste artigo

Tabela 8: Preferências entre probabilidades positivas e negativas com possibilidades de $45 \%$ e $90 \%$ de ganho ou perda para investidores portugueses

\begin{tabular}{|c|c|c|c|c|c|c|c|}
\hline & \multicolumn{2}{|c|}{ Escolha Entre } & \multirow[b]{2}{*}{ Total } & & \multicolumn{2}{|c|}{ Escolha Entre } & \multirow[b]{2}{*}{ Total } \\
\hline & $\begin{array}{c}\text { - Risco } \\
\text { (A) } \\
\text { Um bilhete de } \\
\text { loteria com proba- } \\
\text { bilidade de } 90 \% \text { de } \\
\text { ganhar } \$ 3.000,00 \text {. }\end{array}$ & $\begin{array}{c}\text { + Risco } \\
\text { (B) } \\
\text { Um bilhete de loteria } \\
\text { com probabilidade } \\
\text { de } 45 \% \text { de ga- } \\
\text { nhar } \$ 6.000,00 .\end{array}$ & & & $\begin{array}{c}\text { - Risco } \\
\text { (A) } \\
\text { A probabilidade de } 90 \% \\
\text { de perder } \$ 3.000,00 .\end{array}$ & $\begin{array}{c}\text { + Risco } \\
\text { (B) } \\
\text { A probabilidade } \\
\text { de } 45 \% \text { de perder } \\
\$ 6.000,00 .\end{array}$ & \\
\hline Total & $76,2 \% *$ & $23,8 \% *$ & $100 \%$ & Total & $30,0 \% *$ & $70,0 \% *$ & $100,0 \%$ \\
\hline
\end{tabular}

Fonte: Elaborada pelos autores deste artigo

Na Tabela 7, no primeiro problema ligado ao campo dos ganhos, um percentual maior de investidores $(52,30 \%)$ optou por ganhar $\$ 3.000,00 \mathrm{com}$ probabilidade de $25 \%$ a correr um maior risco para tentar ganhar $\$ 4.000,00$ com probabilidade de $20 \%$. No entanto, essa diferença não é significativa ao nível de $5 \%$. Por outro lado, no campo das perdas, $40,0 \%$ prefeririam perder $\$ 4.000,00$ com $20 \%$ de probabilidade contra $60,0 \%$ dos participantes que preferiram perder $\$ 3.000,00$ com $25 \%$ de probabilidade.

Nas situações positivas de ganho, como a diferença não é significativa, não é possível afirmar se houve aversão ou propensão ao risco no campo dos ganhos. Porém, no campo das perdas, os investidores portugueses optaram pelo grau de risco maior no campo das perdas demonstrando assim uma propensão ao risco no campo das perdas.

Para confirmar esse efeito, na Tabela 8 foram analisadas as mesmas questões, porém com probabilidades de $45 \%$ e $90 \%$ de ganho ou perda.
Na Tabela 8 é possível verificar que a grande maioria dos investidores portugueses apresentaram aversão ao risco no campo dos ganhos, uma vez que $76,20 \%$ optou por uma probabilidade de $90 \%$ de ganhar \$3.000,00 contra $23,8 \%$ dos que optaram por uma probabilidade de $45 \%$ de ganhar $\$ 6.000,00$, mantendo uma aversão ao risco no campo dos ganhos.

Já no campo das perdas, a maioria $(70,0 \%)$ optou por arriscar mais, ao escolher uma probabilidade de $45 \%$ de perder $\$ 6.000,00$, confirmando assim a propensão ao risco no campo das perdas.

Devido à assimetria das preferências dos investidores nos problemas de probabilidades positivas (campo dos ganhos) e negativa (campo das perdas) foi possível constatar que os participantes desta pesquisa são avessos ao risco no campo dos ganhos e propensos ao risco no campo das perdas. De acordo com o efeito reflexo, no campo das perdas, as pessoas tendem a arriscar a sofrerem uma perda certa. Kahneman e Tversky (1979) descobriram que os sinais 
dos resultados quando são invertidos em ganhos para perdas, as pessoas se tornam propensas ao risco e que tal comportamento fere o axioma da TUE de aversão ao risco. Assim, é possível afirmar que ocorreu o efeito reflexo na presente pesquisa.

\section{Considerações Finais}

A investigação central deste artigo buscou conhecer por meio do estudo das finanças comportamentais quais as preferências frente ao mercado financeiro de estudantes de stricto sensu de Lisboa - Portugal.

As teorias comportamentais analisam de forma isolada diversos padrões de comportamento como, por exemplo: excesso de confiança, otimismo, efeito manada, aversão à perda, aversão ao arrependimento, entre outros. Ainda não se conseguiu formular um modelo que englobasse todos os padrões.

Os estudos existentes comprovam que eles afetam o comportamento dos indivíduos de forma isolada, mas ainda não se conseguiu provar que estas anomalias afetam o mercado como um todo. As Finanças comportamentais em seu desenvolvimento ainda necessitam definir alguns conceitos e resolver algumas incoerências, mas principalmente a elaboração de um modelo matemático confiável e abrangente.

Esta pesquisa possibilitou verificar que os estudantes de stricto sensu de Lisboa estão praticando investimentos e que maioria possui características de investidores com perfis conservador e moderado. Entretanto, não foi observada uma relação entre as variáveis: idade, tempo de investimento e renda individual e o perfil do investidor.

Contudo, diante do exposto nos resultados desta pesquisa, pode-se inferir que os investidores nem sempre se mantêm racionais em decisões de investimento sob risco. Nos problemas de probabilidades positivas (campo dos ganhos) e negativas (campo das perdas), foi possível constatar que a maioria dos participantes desta pesquisa é avessa ao risco no campo dos ganhos e propensa ao risco no campo das perdas. Assim, é possivel afirmar que ocorreu o efeito reflexo na presente pesquisa.

Devido a restrições geográficas e de tempo, esta pesquisa não entrevistou toda a população de estudantes de stricto sensu. Assim, os resultados encontrados serão válidos apenas para a população investigada referente aos estudantes de stricto sensu dos cursos de Administração, Ciências Contábeis e Economia de Lisboa.

Para trabalhos futuros, a sugestão versa na possibilidade de replicação desses estudos, porém para públicos diferentes, como por exemplo: para investidores não alunos de stricto sensu, para investidores brasileiros ou até mesmo de outros países.

\section{REFERÊNCIAS}

ALLAIS, M. Le compartement de l'homme rationnel devant le risque, critique des postulats et axiomes de l'ecole Americaine. Econometrica, Colombia, v. 21, p. 503-546, 1953.

ARRUDA, Paula Baggio. Uma investigação sobre o efeito disposição. 2006. Dissertação (Mestrado em Engenharia de Produção). Universidade Federal de Santa Catariana, Florianópolis, 2006.

ATMAN, A. P. F; GONÇALVES, Bruna Amin. Influence of the Investor's Behavior on the Complexity of the Stock Market. Brazilian Journal of Physics, v. 42, p. 137145, 2012.

BERNSTEIN, P. L. Desafio aos deuses: a fascinante história do risco. Rio de Janeiro: Campus, 1997.

BERNOULLI, Daniel. Exposition of a new theory on the measurement of risk. Tradução de: Louise Sommer. Econometrica, Colombia, v. 22, p. 23-36, 1954. (Reimpressão do original publicado em 1738)

BARBERIS, Nicholas; SHLEIFER, Andrei; VISHNY, Robert. A model investor sentiment. Journal of Financial Economics, v. 49, n. 3, p. 307-343, 1998.

\section{CARMO, Leonardo Correa. Finanças}

comportamentais: uma análise das diferenças de comportamento entre investidores institucionais e individuais. 2005. 91 f. Dissertação (Mestrado em Administração). Pontifícia Universidade Católica do Rio de Janeiro, Rio de Janeiro, 2005. 
CAVALCANTE, Francisco; MISUMI, Jorge Yoshio;

RUDGE, Luiz Fernando. Mercado de capitais: o que é, como funciona. 6. ed. Rio de Janeiro: Campus. 2005

CHIZZOTTI, Antonio. Pesquisa em ciências humanas

e sociais. 9. ed. São Paulo: Cortez, 2008.

COLLIS, Jill; HUSSEY, Roger. Pesquisa em

administração: um guia prático para alunos de graduação e pós-graduação. 2. ed. Porto Alegre.

Bookman. 2005

DIERKES, Maik; ERNER, Carsten; ZEISBERGER, Stefan. Investment horizon and the attractiveness of investment strategies: a behavioral approach. Journal of Banking \& Finance, v. 34, n. 5, p. 1.032-1.046, may 2010.

EDWARDS, William. Conservatism in human information processing. In: KLEINMUNTZ, B. Formal representation of human judgment. New York: Wiley, 1968.

FERREIRA, et al. A Aplicação das finanças comportamentais no processo de tomada de decisão dos investidores no mercado de capitais. II SEMINÁRIO UFPE DE CIÊNCIAS CONTÁBEIS, Recife, Artigo 14, setembro 2008. Anais... Recife, 2008.

GAVA, Alexandre Majola; VIEIRA, Kelmara Mendes. Tomada de decisão em ambiente de risco: uma avaliação sob a ótica comportamental. Read, ed. 49 , v. 12 , n. 1 , jan.-fev. 2006.

\section{GIL, Antônio C. Métodos e técnicas em pesquisa} social. São Paulo: Atlas, 1999.

HALFELD, Mauro. Investimentos: como administrar melhor seu dinheiro. São Paulo: Fundamentos, 2005.

HAUGEN, Robert A. Os segredos da bolsa. São Paulo: Pearson Education, 2000.

KAHNEMAN, Daniel; TVERSKY, Amos. Prospect theory: an analysis of decision under risk. Econometrica, v. 47, n. 2, p. 263-29, mar. 1979.

KAHNEMAN, P. Slavic; TVERSKY, Amos. Judgment under uncertainty: heuristics and biases. Cambridge: Cambridge University Press, 1974.

LINTNER, G. Behavioral finance: why investors make bad decisions. The Planner, v. 13, n. 1, p. 7-8, 1998.
LIMA, Murilo Valverde. Um estudo sobre finanças comportamentais. RAE Eletrônica, [on-line] v. 2, n. 1, jan.-jun. 2003.

MACEDO, Jurandir Sell. Teoria do prospecto: uma investigação utilizando simulação de investimentos. 2003. Tese (Doutorado em Engenharia de Produção e Sistemas). Universidade Federal de Santa Catarina, Florianópolis, 2003.

\section{MINETO, C. A. L. Percepção ao risco e efeito}

disposição: uma análise experimental da Teoria dos Prospectos. Tese de Doutorado, UFSC, Florianópolis, 2005.

OLIVEIRA, E. de; SILVA, S. M. da; SILVA, W. V. da. Finanças comportamentais: um estudo sobre o perfil comportamental do investidor e do propenso investidor. In: II Seminário de Gestão de Negócios da FAE Business School, Curitiba, 2005.

PLOUS, Scott. The psychology of judgment and decision making. McGraw-Hill, 1993.

SAVAGE, L. The foundations of statistics. New York: Wiley, 1964.

SHEFRIN, Hersh. Beyond greed and fear. Harvard Business School Press, 2000.

SKINNER, B. F. Verbal behaviour. Appleton-CenturyCrofts, New York, 1957.

STENBERG, Robert J. Psicologia cognitiva. 4. ed. Porto Alegre: Artmed, 2008.

THALER, R.; SHEFRIN, Hersh. An economic theory of self-control. Journal of Political Economy 1981.

THALER, Richard H. (Ed.). Advances in behavioral

finance. New York: Russell Sage Foundation, 1993.

TOSCANO JÚNIOR, Luis Carlos. Guia de referência para o mercado financeiro. São Paulo: Edições Inteligentes, 2004.

YOSHINAGA, Claudia Emiko et al. Finanças comportamentais: uma introdução. Revista de Gestão USP, São Paulo, v. 15, n. 3, p. 25-35, jul.-set. 2008. 
Finanças Comportamentais: uma investigação com base na teoria do prospecto e no perfil do investidor de estudantes de cursos stricto sensu ...

\section{ZINDEL, Márcia Terezinha Longen. Finanças}

comportamentais: o viés cognitivo excesso de confiança em investidores e sua relação com as bases biológicas. 2008. Tese (Doutorado em Engenharia de Produção). Universidade Federal de Santa Catarina, Florianópolis, 2008. 